\title{
Characterization of phytoconstituents and evaluation of antimicrobial activity of silver- extract nanoparticles synthesized from Momordica charantia fruit extract
}

Md. Mamun Or Rashid ${ }^{1 *}$, Kazi Nahid Akhter ${ }^{1}$, Jakir Ahmed Chowdhury², Foysal Hossen ${ }^{3}$, Md. Saddam Hussain ${ }^{1}$ and Md. Tanvir Hossain ${ }^{4}$

\begin{abstract}
Background: Our present study was conducted to characterize the phytoconstituents present in the aqueous extract of Momordica charantia and evaluate the antimicrobial efficacy of silver-extract nanoparticles (AgExtract-NPs).

Methods: Silver nanoparticles (AgNPs) were prepared by reducing $\mathrm{AgNO}_{3}$; and $\mathrm{NaBH}_{4}$ served as reducing agent. After screening of phytochemicals; AgNPs and aqueous extract were mixed thoroughly and then coated by polyaniline. These NPs were characterized by using Visual inspection, UV spectroscopy, FTIR, SEM and TEM techniques. Antimicrobial activities were assessed against Staphylococcus aureus, Salmonella typhi, Escherichia coli and Pseudomonas aeruginosa.
\end{abstract}

Results: Aqueous extract of M. charantia fruits contain alkaloid, phenol, saponin etc. UV-Vis spectrum showed strong absorption peak around $408 \mathrm{~nm}$. The presence of $-\mathrm{CH},-\mathrm{NH},-\mathrm{COOH}$ etc. stretching in FTIR spectrum of Ag-Extract-NPs endorsed that AgNPs were successfully capped by bio-compounds. SEM and TEM result revealed that synthesized NPs had particle size 78.5-220 nm. Ag-Extract-NPs showed $34.6 \pm 0.8 \mathrm{~mm}$ zone of inhibition against $E$. coli compared to $25.6 \pm 0.5 \mathrm{~mm}$ for ciprofloxacin. Maximum zone of inhibition for AgExtract-NPs were $24.8 \pm 0.7 \mathrm{~mm}, 26.4 \pm 0.4 \mathrm{~mm}, 7.4 \pm 0.4 \mathrm{~mm}$ for S. aureus, P. aeruginosa and S. typhi. We found that Ag-Extract-NPs have much better antibacterial efficacy than AgNPs and M. charantia extract has individually. It is also noticed that gram negative bacteria (except S. typhi) are more susceptible to Ag-ExtractNPs than gram positive bacteria.

Conclusion: Ag-Extract-NPs showed strong antibacterial activity. In order to make a reliable stand for mankind, further study is needed to consider determining the actual biochemical pathway by which AgNPsextracts exert their antimicrobial effect.

Keywords: Silver nanoparticles (AgNPs), Silver extract nanoparticles (Ag-extract-NPs), M. charantia, Antibacterial activity

\footnotetext{
* Correspondence: mamun_nstu@yahoo.com

${ }^{1}$ Department of Pharmacy, Noakhali Science and Technology University,

Sonapur, Noakhali 3814,, Bangladesh

Full list of author information is available at the end of the article
} 


\section{Background}

Nanoparticle research has become an area of intense scientific interest due to a wide variety of potential applications in electronic, optical and biomedical fields $[1,2]$. It is found that nanoparticles have the capability to fix, adsorb and carriage other compounds such as drugs, probes and proteins because of their large surface area [3].

Nowadays, the generation of antibiotic-resistant bacteria has become the greatest health challenges and serious concerns to be considered [4]. In recent times, nanoparticle technology got the pin point in the development of new antimicrobial agent which is successfully used against antibiotic-resistant bacterial strain. It is great to see in recent year various keyboards, wound dressings, textiles, and biomedical devices containing silver nanoparticles are generated which provide protection against bacteria through continuous release of low level of silver ions [5]. Numerous types of nanomaterials and their composites have been applied as antimicrobial agents such as titanium, copper, zinc, gold, and silver [6-9]. Despite some actual concernment, regarding their toxicity [10], AgNPs demonstrate very good antimicrobial activity against bacteria, viruses, and other eukaryotic microorganisms [11]. Several studies have afforded to explicate the biochemical pathway by which AgNPs pose their antibacterial activities [12-14]. It is supposed that large surface area of NPs and their capability to successfully release silver ions is the pin point to their antibacterial activity [15]. The discharge of ionic silver causes cell death through inactivation of vital bacterial enzymes, inhibition of DNA replication, and by rupturing the bacterial cytoplasmic membranes [12].

Momordica charantia commonly known as bitter gourd is a tropical and subtropical vine of the family Cucurbitaceae, widely grown in Asia, Africa and the Caribbean for its edible fruit, which is extremely bitter in taste [16]. Different parts of the plant are medicinally used to recover from diabetes and also used in following aspects such as antibilious, stomachic, emetic, anthelmintic agent, laxative, for the treatment of skin diseases, cough, wounds, gout, ulcer, respiratory diseases and rheumatism [17]. Present study is designed to characterize the phytoconstituents present in $M$. charantia and the antibacterial activity of $M$. charantia extract loaded AgNPs.

\section{Methods}

\section{Materials collection}

Fresh unripe fruits of $M$. charantia were collected from the local market of Noakhali, Bangladesh. Later, these were washed thoroughly by distilled water several times. The plant's material was identified and authenticated by the National Harberium, Mirpur, Dhaka.
The voucher specimen no. was DACB 42292. Silver Nitrate (MERCK, Germany), $\mathrm{NaBH}_{4}$ (LOBA CHEMIE), aniline and all other chemicals used in this experiment were analytical grades and collected from the laboratory of the Department of Pharmacy, Noakhali Science and Technology University.

\section{Extract preparation}

About $200 \mathrm{~g}$ fresh bitter gourds were collected from Noakhali district of Bangladesh. The fruits were washed thoroughly with double distilled water, cut into fine pieces and boiled with $1000 \mathrm{~mL}$ distilled water for about $1 \mathrm{~h}$. The extract was cooled at room temperature and filtered by cotton and Whatman filter paper. Prepared clear extract was stored in refrigerator at $4{ }^{\circ} \mathrm{C}$ for further use.

\section{Phytochemical screening}

The extract solution was used for preliminary screening of phytochemical such as alkaloids, tannin, phenolic compound, saponin, glycoside, flavonoid, protein, reducing sugar, phytosterol, gum and mucilage etc. by using standard procedures described by Mbaebie et al. [18].

\section{Synthesis of silver nanoparticles}

As described in our previous paper [16], Ag nanoparticles were prepared according to the recipe described in the literature of Creighton, 1979 with slight modification [19]. Briefly, $34 \mathrm{mg}\left(1.0 \times 10^{-3} \mathrm{M}\right)$ AgNO3 was added with $200 \mathrm{~mL}$ double distilled water and $45.4 \mathrm{mg}\left(2.0 \mathrm{X} \quad 10^{-3} \mathrm{M}\right) \mathrm{NaBH}_{4}$ was added with $600 \mathrm{~mL}$ double distilled water. After chilling the solutions at $0{ }^{\circ} \mathrm{C}$, mixing was done with continuous stirring for $1 \mathrm{~h}$. Due to mixing, Ag ions were reduced and formed mono-dispersed nanoparticles. At this point this solution of Ag nanoparticles was so stable that it did not change color for a long time without any stabilizing agent. Solution was concentrated 10 times using a rotary vacuum evaporator as particle concentration of the solution was very low.

\section{Preparation of Ag-extract-NPs}

Extract and Ag nanoparticles solutions were mixed continuously for $30 \mathrm{~min}$ by magnetic stirrer and then kept for $2 \mathrm{~h}$. Due to mixing, silver nanoparticles were loaded with extract to form Ag-Extract-NPs. This uncoated AgExtract-NPs need to be coated for making it more stable.

\section{Coating of Ag-extract-NPs by polyaniline}

Coating on the Extract-AgNPs were done according to the Rashid et al. [20]. $2.7 \mathrm{~g}$ aniline was dissolved into $300 \mathrm{~mL}$ deionized water. At the same time, $68 \mathrm{~mL}(6 \%)$ 
of $\mathrm{H}_{2} \mathrm{O}_{2}$ was also prepared. These two solutions were added slowly with uncoated Ag-Extract-NPs at room temperature for $30 \mathrm{~min}$. The mixture was allowed to stir continuously for $23 \mathrm{~h}$. The final product was filtered, washed by distilled water and then dried at room temperature. Finally, Ag-Extract-NPs were ready for further analysis (antimicrobial activity).

\section{Characterization studies}

Prepared AgNPs need to be characterized for confirming those as nanoparticles. Color changes during experiment endorsed the formation of nanoparticles. Reduction of pure silver ions was monitored by measuring UV-Vis spectra of the reaction mixture. UV-Vis spectra were measured using Hitachi, U-2800 spectrophotometer model (UV- Visible double beam). For characterizing, absorption spectra of the samples were taken 200 to $700 \mathrm{~nm}$. FTIR spectra (IR Prestige-21, Shimadzu) were also performed and recorded in the range of $4000-400 \mathrm{~cm}^{-1}$ at a resolution of $4 \mathrm{~cm}^{-1}$. Size, shape and morphology of nanoparicles were determined by using Scanning Electron Microscopy (2600SN Hitachi, Japan) from BCSIR, Bangladesh and Transmission Electron Microscopy (HITACHI H-700, Japan) images were taken from the Departmental laboratory of Applied Chemistry and Biochemistry, Kumamoto University, Japan.

\section{Test microorganisms}

Authentic pure cultures of Staphylococcus aureus ATCC 25923, Salmonella typhi ATCC 14028, Escherichia coli ATCC 25922 and Pseudomonas aeruginosa ATCC 27853 were obtained from the department of microbiology, NSTU, Bangladesh.

\section{Antimicrobial activity using Kirby-Bauer's disc diffusion method}

Antibacterial activities of the Ag-Extract-NPs were determined using a modified Kirby-Bauer's disc diffusion method [21]. Solutions of known concentration of the test samples were made by dissolving a measured amount of the samples in a calculated amount of solvents. Dried and sterilized filtered paper discs (6 $\mathrm{mm}$ diameter) were then impregnated with known amounts of the test substances using micropipette. The discs containing tested material were placed on Muller-Hinton agar media which were inoculated with test microorganisms previously. Ciprofloxacin discs (standard) and blank discs (impregnated with solvents) were used as positive and negative control. Agar plates were then allowed to stand at $4{ }^{\circ} \mathrm{C}$ for $2 \mathrm{~h}$ before incubation. During this time dried discs can absorb water from the surrounding media and then test materials were dissolved and diffused out of the sample disc. Plates were incubated at $37{ }^{\circ} \mathrm{C}$ for $24 \mathrm{~h}$ to allow maximum growth of the organisms. The antimicrobial activities of the test agents were determined by measuring of zone of inhibition expressed in millimeter.

\section{Statistical analysis}

Data were analyzed using one way ANOVA tests (SPSS software, version-20) followed by Dennett's t-tests. $" p<0.05, * * p<0.01,{ }^{* * * * *} p<0.005$ were considered significant.

\section{Result and discussion}

\section{Phytochemical composition of $M$. charantia}

Phytochemical screening of aqueous extract of $M$. charantia is shown in Table 1. Result revealed that the extract contains remarkable amount of alkaloid, phenolic and saponin compounds. In addition, we also found the presence of tannin, glycoside, protein, reducing sugar etc. in the aqueous extract of $M$. charantia.

\section{Characterization of AgNPs \\ Assessment of AgNPs through visual assessment}

Prepared silver nanoparticles were evaluated first by visual assessment. Due to reaction within $20 \mathrm{~min}$, color of the mixture turned into dark brown from its initial brownish yellow color. Such color change indicated the formation of silver nanoparticles due to the reduction of $\mathrm{AgNO}_{3}$.

\section{Assessment of AgNPs by UV spectrum}

The reaction mixture was allowed to UV-Vis spectrum at different wavelengths ranging from 300 to $700 \mathrm{~nm}$. Strong absorption peak centering at approx. $408 \mathrm{~nm}$ (Fig. 1) was found, which indicated the formation of AgNPs.

Table 1 Phytochemical analysis of aqueous extract of M. charantia fruits

\begin{tabular}{lll}
\hline Phytochemical & Test name & $\begin{array}{l}\text { Aqueous extract of } \\
\text { M. charantia }\end{array}$ \\
\hline Alkaloid & Meyer Test & + \\
& Wagner Test & ++ \\
Phenolic & Ferric Chloride Test & + \\
& Lead Acetate Test & ++ \\
Tanins & Ferric Chloride Test & + \\
& Potassium Dicromate Test & - \\
Saponin & Froth's Test & ++ \\
Glycoside & Keller Kilani Test & + \\
Protein & Xanthroprotic Test & + \\
Reducing Sugar & Fehling's Test & + \\
Phytosterol & Liebermann-Burchard's Test & - \\
\hline
\end{tabular}

Here,$++=$ Moderate; $+=$ Normal Concentration; $-=$ Absent 


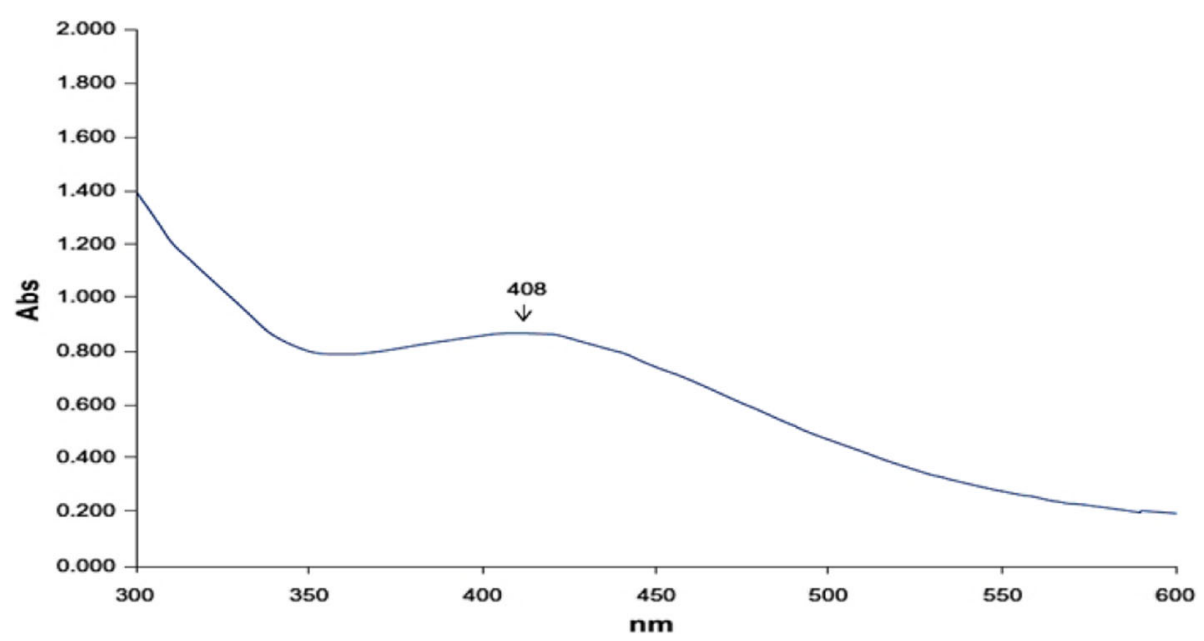

Fig. 1 UV-Vis spectrum of AgNPs

\section{Assessment of Ag-extract-NPs through FTIR spectra}

The FTIR spectra were used for confirming the possibility of capping by $M$. charantia extract on AgNPs. The possible functional groups of leaf extract involved in coating nanoparticle are identified by FTIR analysis which is shown in Fig. 2. The intense absorption peaks at $2926.01 \mathrm{~cm}^{-1}$ and $2870.08 \mathrm{~cm}^{-1}$ (curve-1) and $2916.37 \mathrm{~cm}^{-1}$ (curve-2) correspond to $-\mathrm{C}-\mathrm{H}$ stretching of alkane. The band observed at $3354.21 \mathrm{~cm}^{-1}$ (curve-2) is for N-H stretching of primary amine. The band observed at $2358.94 \mathrm{~cm}^{-1}, 2341.58 \mathrm{~cm}^{-1}$ (curve-1) and $2426.45 \mathrm{~cm}^{-1}, 2358.94 \mathrm{~cm}^{-1}, 2341.58 \mathrm{~cm}^{-1}$ (curve-2) represent the presence of $-\mathrm{COOH}$ group which may exist in the fruit extract of $M$. charantia and Ag-Extract-NPs.
In addition, stretching for alkene $(-\mathrm{C}=\mathrm{C}$-) was found at $1654.92 \mathrm{~cm}^{-1}$ (curve-1) and $1666.50 \mathrm{~cm}^{-1}$ (curve-2). The peak found at $1470.50 \mathrm{~cm}^{-1}$ (curve-1) and $1479.40 \mathrm{~cm}^{-1}$ (curve-2) correspond to $-\mathrm{CH}$ scissoring.

The band observed at $1384.89 \mathrm{~cm}^{-1}$ (curve-2) represent $\mathrm{N}=\mathrm{O}$ stretching of nitro groups and $1253.73 \mathrm{~cm}^{-1}$ (curve-2) indicate the presence of alkyl halide or alcohol group in fruit extract coated on nanoparticles. The arising of functional groups in FTIR spectrum indicates proper coating of leaf extract on silver nanoparticles. The bands at $1130.29 \mathrm{~cm}^{-1}$ (curve-2) denoted -C-H stretching vibration of ester. Beside, C-O stretch occurred at $1001.01 \mathrm{~cm}^{-1}$. The bands at $754.17 \mathrm{~cm}^{-1}$, $711.50 \mathrm{~cm}^{-1}, 678.94 \mathrm{~cm}^{-1}, 670.25 \mathrm{~cm}^{-1}$ (curve-1) and

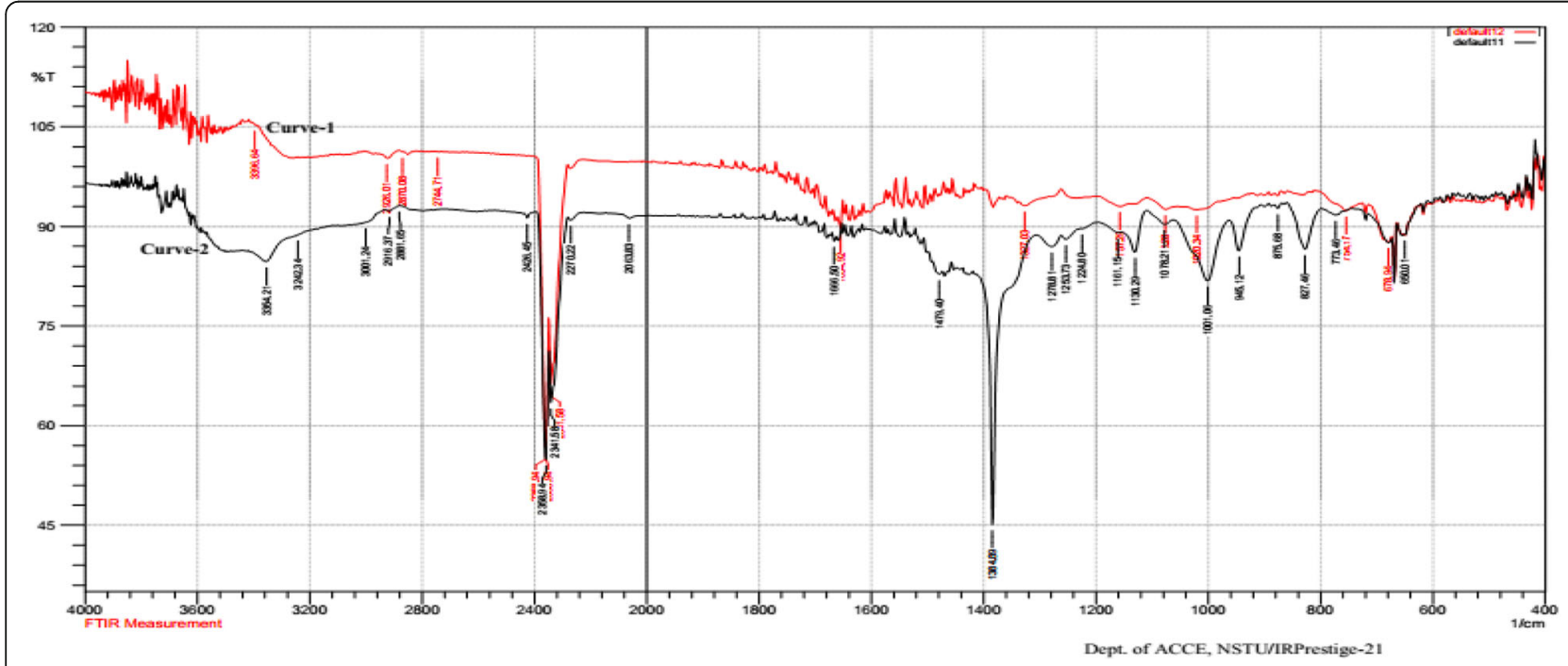

Fig. 2 FTIR spectrum of M. charantia extract (Curve-1) and Ag-Extract-NPs (Curve-2) 


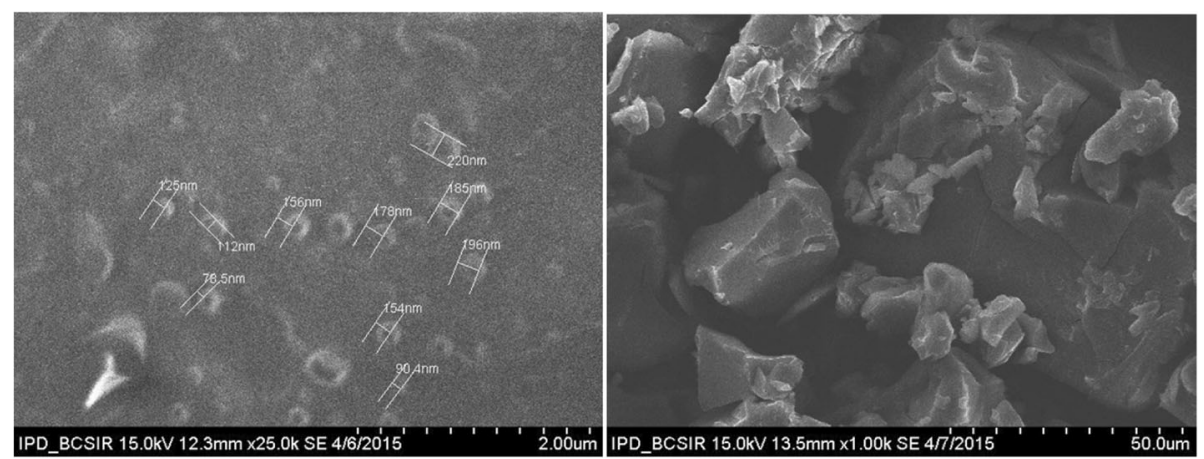

Fig. 3 SEM image of Ag-Extract-NPs

$827 \mathrm{~cm}^{-1}, 678.94 \mathrm{~cm}^{-1}, 670.25 \mathrm{~cm}^{-1}$ represent the ortho substituted and mono substituted aromatic stretching respectively. The FTIR results imply that aqueous fruit extract of $M$. charantia was successfully capped on AgNPs and Ag-Extract-NPs were successfully synthesized.

\section{Assessment of Ag-extract-NPs by SEM and TEM imaging}

SEM and TEM analysis gave us information about structural morphology, size and shape of the synthesized Ag-Extract-NPs (Figs. 3 and 4). It was found that the Ag-Extract-NPs were roughly circular in most of the cases; however in few cases they were irregular. The diameter of these nanoparticles lied between 78.5 to $100 \mathrm{~nm}$ in most cases, however few particles were larger than average diameter. The nanoparticles were not in direct contact with each other even within the aggregates, indicating stabilization of the nanoparticles by a capping agent. The larger particles found in SEM measurements were probably due to the aggregation of the smaller ones.

\section{Assessment of in-vitro antibacterial activity}

Antibacterial activities of aqueous extract of $M$. charantia, AgNPs, Ag-Extract-NPs were tested against both gram positive and negative bacteria. The zone of inhibition due to their antibacterial efficacy were measured and shown in Table 2 , Fig. 5 (see details in Additional file 1: Table S1). It was found that maximum zone of inhibition produced by $M$. charantia extract, AgNPs and Ag-Extract-NPs were $16.6 \pm 0.5 \mathrm{~mm}$, $14.4 \pm 0.5 \mathrm{~mm}$ and $24.8 \pm 0.7 \mathrm{~mm}$ respectively when tested against gram positive strain $S$. aureus. Ciprofloxacin $(20 \mu \mathrm{g} / \mathrm{mL})$ served as standard which produced $23.2 \pm 0.4 \mathrm{~mm}$ zone of inhibition. Again, maximum zone of inhibition against E. coli by Extract, AgNPs, AgExtract-NPs were $28.0 \pm 0.9 \mathrm{~mm}, 20.6 \pm 0.9$, $34.6 \pm 0.8 \mathrm{~mm}$ respectively. $S$. typhi showed resistant against the tested material as they couldn't produce remarkable zone of inhibition. Finally, $20.6 \pm 0.7 \mathrm{~mm}$, $20.0 \pm 0.6 \mathrm{~mm}, 26.4 \pm 0.4 \mathrm{~mm}$ zone of inhibition were produced by Extract, AgNPs, Ag-Extract-NPs against $P$. aeruginosa. Ciprofloxacin was used as standard in all cases. In most cases, it was found that Ag-ExtractNPs produced much better zone of inhibition than AgNPs and $M$. charantia extract produced individually. S. typhi is more resistant to Ag-Extract-NPs than other gram negative bacteria tested in this study.

The antimicrobial action AgNPs on microorganisms is partially known. Silver nanoparticles possess positive

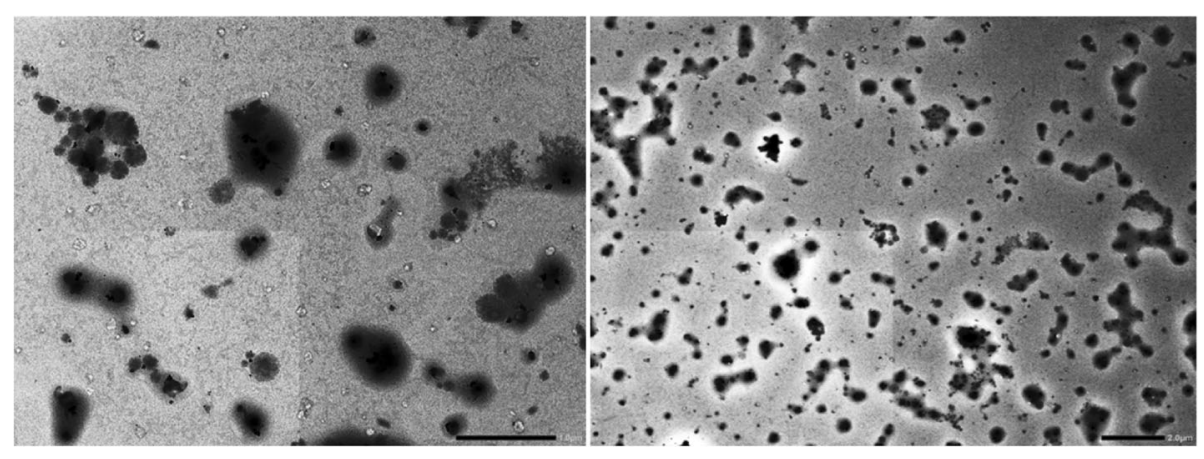

Fig. 4 TEM image of Ag-Extract-NPs 

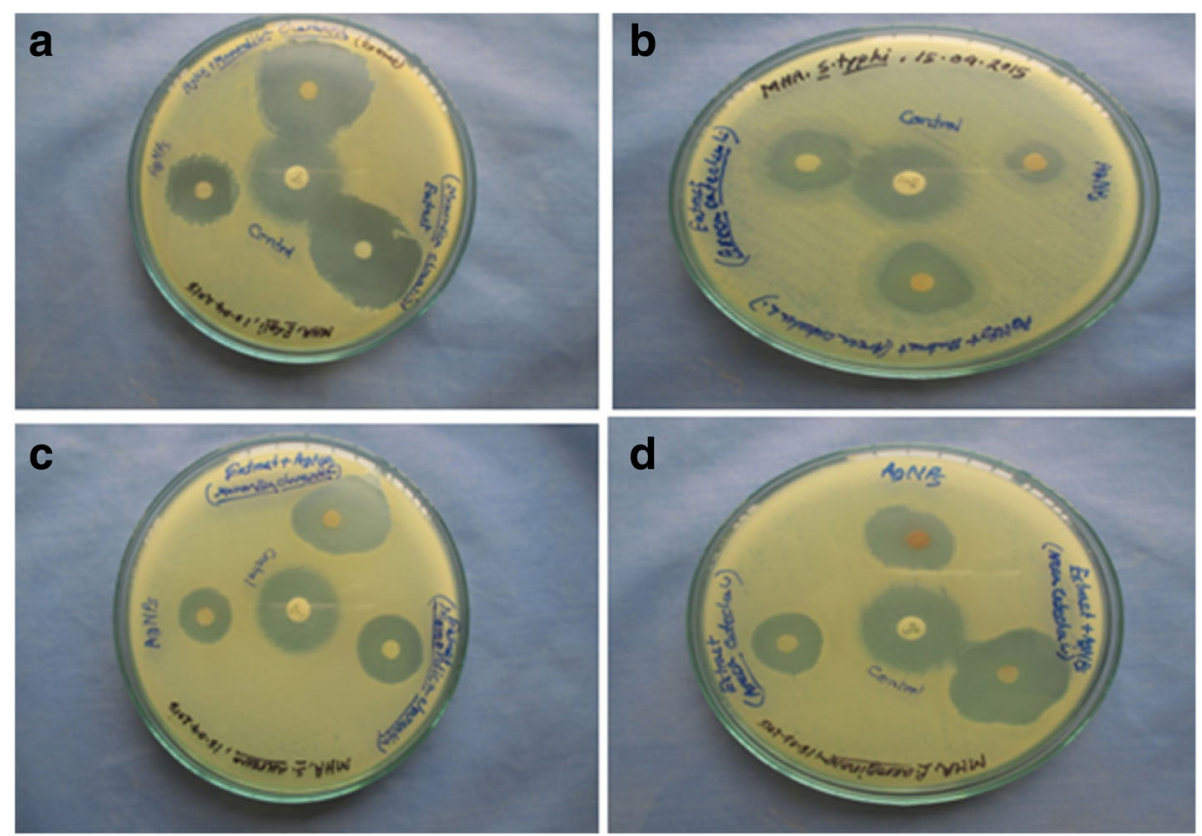

Fig. 5 Antibacterial activities of M. charantia, AgNPs, Ag-Extract-NPs against- a E. coli b S. typhi c S. aureus $\mathbf{d} P$. aeruginosa

charge which can be attached with negative charged components in cell wall of microorganisms by the electrostatic attraction. Moreover, silver nanoparticles are associated with the thiol groups of cell wall resulted in the generation of reactive oxygen species and destroy the cell wall. In addition, AgNPs can improve the permeability of cell wall by pit formation. As a result, internal materials can leak out and cell may die [5, 22]. On the other hand, fruit extract of $M$. charantia contains of glycosides, saponins, alkaloids, reducing sugars, resins, phenolic constituents, fixed oil and free acids [16]. These phytochemicals can attach with the cell proteins and disrupt their synthesis.

The combine antibacterial efficacy of AgNPs and $M$. charantia (Ag-Extract-NPs) is much better than the effect produced by AgNPs and Extract individually. Perhaps, when the bioactive phytoconstituents of $M$. charantia extract were capped on AgNPs, they produced synergistic effect. As a result, Ag-Extract-NPs can produce strong antibacterial effect.

\section{Conclusion}

In summary, our study shows that Ag-Extract-NPs have excellent antibacterial efficacy both gram positive and negative bacteria. Although, AgNPs and M. charantia both possess antimicrobial effect, combination of these two in form of Ag-Extract-NPs showed synergistic effect which is much better than individual effects. This green and safe method may become effective against the resistant bacteria species which is a much concerning issue of medical science now-adays. However, further investigation is needed on human model to warrant this finding for potential therapeutic effects.

Table 2 Antibacterial activity of M. charantia extract, AgNPs and Ag-Extract-NPs

\begin{tabular}{lllll}
\hline Items & Zone of inhibition $(\mathrm{mm})$ & & \\
\cline { 2 - 5 } & S. aureus & S. typhi & E. coli & P. aeruginosa \\
& ATCC 25923 & ATCC 14028 & ATCC 25922 & ATCC 27853 \\
\hline M. charantia extract $(50 \mu \mathrm{g} / \mathrm{ml})$ & $16.6 \pm 0.5^{* * *}$ & $8 \pm 0.3^{* * *}$ & $28.0 \pm 0.9^{*}$ & $20.6 \pm 0.7^{* * *}$ \\
AgNPs $(50 \mu \mathrm{g} / \mathrm{ml})$ & $14.4 \pm 0.5^{* * *}$ & $6.4 \pm 0.4^{* * *}$ & $20.6 \pm 0.9^{* * *}$ & $20.0 \pm 0.6^{* * *}$ \\
Ag-Extract-NPs $(50 \mu \mathrm{g} / \mathrm{ml})$ & $24.8 \pm 0.7^{* * *}$ & $7.4 \pm 0.4^{* * *}$ & $34.6 \pm 0.8^{* * *}$ & $26.4 \pm 0.4^{*}$ \\
Ciprofloxacin $(20 \mu \mathrm{g} / \mathrm{ml})$ & $23.2 \pm 0.4$ & $21.4 \pm 0.5$ & $25.6 \pm 0.5$ & $25.2 \pm 0.4$ \\
\hline
\end{tabular}

Mean \pm SEM $(n=5)$; Data was analyzed using one way ANOVA followed by Dunnet's t-test and compared with standard. ${ }^{*} p<0.05,{ }^{* *} p<0.01,{ }^{* * *} p<0.005$ were considered significant 


\section{Additional file}

Additional file 1: Table S1. Antibacterial efficacy of $M$. charantia, AgNPs and Ag-Extract-NPs. (XLSX $13 \mathrm{~kb}$ )

\section{Abbreviations}

Ag-Extract-NPs: Silver extract nanoparticles; AgNPs: Silver nanoparticles; FTIR: Fourier Transform Infrared Spectroscopy; NPs: Nanoparticles; NSTU: Noakhali Science and Technology University; SEM: Scanning Electron Microscopy; TEM: Transmission Electron Microscopy; UV: Ultraviolet

\section{Acknowledgements}

The authors are very grateful to Departmental laboratory of Applied Chemistry and Biochemistry, Kumamoto University, Japan; and the teachers, staffs (technical and non-technical) of the Department of Pharmacy, Noakhal Science and Technology University, Noakhali, Bangladesh for their valuable support.

\section{Funding}

Funding for this research is found as NST (National Science and Technology) scholarship granted by Ministry of Science and Technology, Bangladesh for a graduate student of Pharmacy, NSTU, Bangladesh.

\section{Availability of data and materials}

All data and materials are contained and described within the manuscript. The data set was deposited in publicly available repositories. The plant's materials for the study were identified and voucher specimens are deposited by the National Harberium, Mirpur, Dhaka, Bangladesh.

\section{Authors' contributions}

MMOR has prepared the study design and write the manuscript. KNA and $\mathrm{FH}$ participated in experiments. JAC read and revised the manuscript for improving the quality of final manuscript. MSH checked the grammatical mistakes, helps to analyze the data in the final manuscript. MTR helped to manage the image of FTIR and TEM. All authors read and approved the final version of the manuscript.

\section{Authors' information}

Md. Mamun Or Rashid is Assistant Professor, Department of Pharmacy; Foysal Hossen is Assistant Professor, Department of Microbiology and Md. Tanvir Hossain is Assistant Professor, Applied Chemistry and Chemical Engineering, Noakhali Science and Technology University, Bangladesh. Jakir Ahmed Chowdhury, Associate Professor, Department of Pharmaceutical Technology, University of Dhaka, Bangladesh. Kazi Nahid Akhter and Md. Saddam Hussain are graduate students of Department of Pharmacy, Noakhali Science and Technology University, Bangladesh.

\section{Ethics approval and consent to participate}

Not applicable.

\section{Consent for publication}

Not applicable.

\section{Competing interests}

The authors declare that they have no competing interest.

\section{Publisher's Note}

Springer Nature remains neutral with regard to jurisdictional claims in published maps and institutional affiliations.

\section{Author details}

'Department of Pharmacy, Noakhali Science and Technology University, Sonapur, Noakhali 3814, Bangladesh. ²Department of Pharmaceutical Technology, University of Dhaka, Dhaka 1000, Bangladesh. ${ }^{3}$ Department of Microbiology, Noakhali Science and Technology University, Sonapur, Noakhali 3814 „, Bangladesh. ${ }^{\circ}$ Department of Applied Chemistry and Chemical Engineering, Noakhali Science and Technology University, Sonapur, Noakhali 3814, Bangladesh
Received: 7 February 2017 Accepted: 19 June 2017

Published online: 26 June 2017

\section{References}

1. Taylor R, Coulombe S, Otanicar T, Phelan P, Gunawan A, Wei L, et al. Smal particles, big impacts: a review of the diverse applications of nanofluids. J Appl Phys. 2013;113:011301.

2. Hewakuruppu YL, Dombrovsky LA, Chen C, Timchenko V, Jiang X, Baek S, et al. Plasmonic. "pump-probe" method to study semi-transparent nanofluids. Appl Opt. 2013;52(24):6041-50

3. Jong WHD, Borm PJA. Drug delivery and nanoparticles: applications and hazards. Int J Nanomedicine. 2008;3(2):133-49.

4. Riley MA, Robinson SM, Roy CM, Dennis M, Liu V, Dorit RL. Resistance is futile: the bacteriocin model for addressing the antibiotic resistance challenge. Biochem Soc Trans. 2012:40(6):1438-42.

5. Janaki AC, Sailatha E, Gunasekaran S, Sekar T, Gopalakrishnan M. Synthesis, characteristics and antimicrobial activity of Ag nanoparticles. Int J Adv Sci Technol Eng Manag Sci. 2016;2(5):10-7.

6. Khan ST, Ahamed M, Alhadlaq HA, Musarrat J, Al-Khedhairy A. Comparative effectiveness of $\mathrm{NiCl} 2, \mathrm{Ni}$ - and $\mathrm{NiO}-\mathrm{NPs}$ in controlling oral bacterial growth and biofilm formation on oral surfaces. Arch Oral Biol. 2013;58(12):1804-11.

7. Chowdhury MNK, Beg MDH, Khan MR, Mina MF. Synthesis of copper nanoparticles and their antimicrobial performances in natural fibres. Mater Lett. 2012:112:841-52.

8. Khan ST, Ahmad M, Al-Khedhairy AA, Musarrat J. Biocidal effect of copper and zinc oxide nanoparticles on human oral microbiome and biofilm formation. Mater Lett. 2013;97:67-70.

9. Perelshtein I, Ruderman E, Perkas N, Tzanov T, Beddow J, Joyce E, et al. Chitosan and chitosan-ZnO based complex nanoparticles: formation, characterization and antibacterial activity. J Mater Chem B. 2013;1(14):1968-76.

10. Seltenrich N. Nanosilver: weighing the risks and benefits. Environ Health Perspect. 2013;121(7):220-5.

11. Rai M, Yadav A, Gade A. Silver nanoparticles as a new generation of antimicrobials. Biotechnol Adv. 2009;27(1):76-83.

12. Feng QL, Wu J, Chen GQ, Cui FZ, Kim TN, Kim JO. A mechanistic study of the antibacterial effect of silver ions on Escherichia coli and Staphylococcus aureus. J Biomed Mater Res. 2000:52(4):662-8.

13. Xiu ZM, Zhang QB, Puppala HL, Colvin VL, Alvarez PJ. Negligible particle-specific antibacterial activity of silver nanoparticles. Nano Lett. 2012;12(8):4271-5.

14. Taglietti A, Diaz Fernandez YA, Amato E, Cucca L, Dacarro G, Grisoli P, et al. Antibacterial activity of glutathione-coated silver nanoparticles against gram positive and gram negative bacteria. Langmuir. 2012;28(21):8140-8.

15. Priyaragini S, Sathishkumar SR, Bhaskararao KV. Biosynthesis of silver nanoparticles using actinobacteria and evaluating its antimicrobial and cytotoxicity activity. Int J Pharm Pharm Sci. 2013:5(2):709-12.

16. Rashid MMO, Ferdous J, Banik S, Islam MR, Uddin AHMM, Robel FN. Anthelmintic Activity of Silver-Extract Nanoparticles Synthesized from the Combination of Silver Nanoparticles and M. charantia Fruit Extract. BMC Complement Altern Med. 2016;16:242.

17. Wang L, Waltenberger B, Pferschy-Wenzig EM, Blunder M, Liu X, Malainer C, et al. Natural product agonists of peroxisome proliferator-activated receptor gamma (PPARY): a review. Biochem Pharmacol. 2014;92(1):73-89.

18. Mbaebie $\mathrm{BO}$, Edeoga $\mathrm{HO}$, Afolayan AJ. Phytochemical analysis and antioxidants activities of aqueous stem bark extract of Schotia latifolia Jacq. Asian Pac J Trop Biomed. 2012;2(2):118-24.

19. Creighton JA, Blatchford CG, Albrecht MG. Plasma resonance enhancement of Raman scattering by pyridine adsorbed on silver or gold sol particles of size comparable to the excitation wavelength. J Chem Soc. 1979:75:790-8.

20. Rashid MMO, Islam MS, Haque MA, Rahman MA, Hossain MT, Hamid MA. Antibacterial activity of polyaniline coated silver nanoparticles synthesized from Piper betle leaves extract. Iran J Pharm Res. 2016;15(2):591-7.

21. Baur AW, Kirby WM, Sherris JC, Turck M. Antibiotic susceptibility testing by a standard single disk method. Am J Clin Path. 1966:45:493-6.

22. Dibrov P, Dzoiba J, Gosink KK, Häse CC. Chemiosmotic mechanism of antimicrobial activity of $\mathrm{Ag}(+)$ in Vibrio cholera. Antimicrob Agents Chemother. 2002;46(8):2668-70 